There were two tongue shaped areas near the lower end of the vertical meridian, apparently either in the posterior layers of the cornea or applied to its posterior surface. The artist has indicated these in the illustration.

The pupil was a vertical slit of a fusiform shape and closely resembled a button-hole with both ends pointed, the iris pattern within the circulus iridis minor corresponding with the pattern made by button-hole stitching. The illustration is from a drawing made by Mr. W. Morse, Art Teacher, Stoke-on-Trent Education Authority.

The edges of the pupillary slit were in constant movement contracting and dilating the pupil.

Under homatropin the pupil became first oval and on full dilatation round.

I am indebted to $\mathrm{Mr}$. E. Treacher Collins for information regarding this defect, particularly for suggesting that remains of pupillary membrane should be looked for, and for a reference to Sir W. R. Wilde's " Essay on the Malformations and Congenital Diseases of the Organs of Sight," published by John Churchill in 1862. In this article a case of double microphthalmia is described. "In both eyes there existed irregularity of the pupil, in form as well as in position, that of the right being triangular, and that of the left being transversely oval."

\title{
ANNOTATIONS
}

\section{Ophthalmic Museums}

A step in the right direction has been taken by Dr. James Moores Ball, of St. Louis, U.S.A., who has given his valuable collection of specimens, books, and instruments to the Army Medical Museum at Washington, D.C. on the several conditions that it is to be kept intact, properly cared for, and is to bear the donor's name. Thus the ophthalmic treasures assembled during a period of thirty years now rest under the aegis of the Government. Under the present arrangements the collection has five divisions: 1, pictorial items; 2 , gross dissections and gross pathology; 3 , microscopical items; 4 , ophthalmic armamentaria; and 5, rare ophthalmic literature. Several gentlemen who belong to this country, including Mr. E. Treacher Collins and Mr. J. Gray Clegg, are ready to contribute to the Ball museum. In describing the steps that have been taken Dr. Ball writes: "It is a pleasure to the writer to give to the Government something it did not possess, something it needed, and something that money could "not buy." (Journ. Missouri State Medical A ssociation, Jan., 1923, p. 37.) 